\title{
Introducing multitasking to the study of travel and ICT: examining its extent and assessing its potential importance
}

\author{
Susan Kenyon* \& Glenn Lyons \\ Centre for Transport \& Society, Faculty of the Built Environment, University of the West of England, \\ Bristol. BS16 1QY. UK. Email: Susan.Kenyon@uwe.ac.uk; Glenn.Lyons@uwe.ac.uk.*Corresponding \\ author. Tel: +44 (0)117328 3996. Fax: +44 (0)1173283002.
}

\begin{abstract}
Personal travel is undertaken principally as a means of access: to opportunities, services, social networks and other goods. The Internet now provides an additional form of access, enabling many activities to be reached without recourse to physical mobility by the individual undertaking the activity. However, the social and transport effects of this 'virtual mobility' are uncertain. Here, it is argued that the incidence and properties of multitasking are a necessary part of the assessment of such impacts. Participation in activities and, thus, change in activity participation will not be fully measured without consideration of the parallel conduct of activities. This paper presents a review, empirical evidence and discussion to support this hypothesis. Emergent from an examination of the literature and examined by new empirical evidence are three observations or hypotheses, namely that: (1), failure to consider multitasking leads to the underreporting of key activities; (2), misrepresentation of activity participation tends to be more pronounced for certain key groups; and (3), lack of awareness of multitasking could lead to the flawed measurement and thus misrepresentation of behaviour change over time. Further to these observations from the literature, study findings suggest that multitasking behaviour is also found to vary according to whether the primary activity is being undertaken online or offline. Taken together, the empirical evidence confirms that the consideration of multitasking is likely to have important implications for the study of travel, Internet use and interactions between the two.
\end{abstract}

Key words: multitasking; accessibility; Internet; ICT; social exclusion; virtual mobility. 


\section{Introduction}

The transport and social impacts of information and communications technologies (ICTs) have been debated for a number of years. The introduction of the Internet into mainstream society and its increasingly popular use over the past ten years, such that two thirds of the UK population now report having used the Internet and more than half report having access to the Internet at home (February 2005) ${ }^{1}$, has intensified this debate ${ }^{2}$. For some, Internet-based 'virtual mobility' - 'a shorthand term for the process of accessing activities that traditionally require physical mobility, but which can now be undertaken without recourse to physical travel by the individual undertaking the activity' (Kenyon et al, 2002) provides a viable alternative to reaching activities by physical movement. Socially, it is hypothesised that this can overcome many aspects of accessibility-related social exclusion, providing access to opportunities, services, social networks and other goods ${ }^{3}$. With regard to transport, it is suggested that, by acting as a substitute for existing or future mobility, virtual mobility can reduce (dependence upon) physical mobility, alleviating transport-related problems including congestion and environmental damage. Equally, however, Internet use has been linked with negative social effects, including reduced social interaction and reduced quality of the activity experience; and with an increase in physical mobility, with associated social effects, as a result of widened travel horizons and increased time available for travel ${ }^{4}$.

Understanding the changing nature (and extent) of the impact of the Internet is, therefore, important for both social and transport policy, because of the effect of a possible increase or decrease in activity participation (including travel) for society. This paper suggests that it could be important to take account of the simultaneous conduct of activities, or 'multitasking', in the exploration of individual behaviour and change therein. Multitasking (it shall be shown) has been the 'forgotten dimension' of time use in travel behaviour research yet, it is contended here, accounting for multitasking can provide a more fully informed understanding of the true extent of activity participation. This, in turn, can present a more accurate picture upon which measures of change can be assessed. Conversely, not accounting for multitasking may perpetuate an incomplete and potentially misleading understanding of activity and thus travel behaviour and of change therein. There are, thus, clear implications of multitasking for travel

\footnotetext{
${ }^{1}$ ONS. 2005. Internet access: $52 \%$ of households online in the UK. Http://www.statistics.gov.uk/cci/nugget.asp?id=8, viewed 26/04/05.

${ }^{2}$ In the wider context of ICTs this paper considers the impact, specifically, of Internet use.

${ }^{3}$ An overview of the principal arguments is presented in Kenyon et al, 2002.

${ }^{4}$ This said, Katz and Rice (2002) highlight the dangers of dividing the debate regarding the impact of the Internet into such 'utopian' and 'dystopian' viewpoints, suggesting that it is equally possible that Internet use will have neither positive nor negative, but null, effect. Anderson and Tracey (2002) present a similar argument.
} 
behaviour research and in particular, this research suggests, for research into the impacts of ICTs upon travel.

In this paper, we define multitasking as the simultaneous conduct of two or more activities during a given time period. In their review of time use research from a transport perspective, embracing the activity-based theory of travel behaviour, Bhat and Koppelman (1999) state: 'Individuals have 24 hours in a day (or multiples of 24 hours for longer periods of time) and decide how to use that time among activities and travel (and with whom) subject to their schedule, socio-demographic, locational and other contextual constraints’. In this statement, Bhat and Koppelman explicitly suggest that all individuals have the same finite number of minutes in the day and, in so doing, implicitly suggest that time is the great equaliser - whilst we can buy and sell the use of time, in the form of labour, we can neither buy nor sell time itself. However, through the double counting of time through multitasking, this paper suggests that individuals are, in fact, able to 'use' more than 24 hours in a day. Following from this, it is suggested that it is possible to increase the number of task-minutes in our days, effectively 'creating' more time, through multitasking. Thus, multitasking can enable individuals to reconfigure their spatio-temporal pattern of activity participation in such a way that participation is more efficient (thereby releasing more time for additional (discretionary) activities), is of higher quality or is more fulfilling.

There are clear implications for activity participation, travel and social equality. With regard to the former, whilst activity-based approaches to travel behaviour embrace the context in which travel occurs, the failure to consider multitasking may lead to inaccurate associations between activities and travel and thus motivations for travel, resulting in the erroneous conceptualisation of behaviour. In turn, it may be important to consider multitasking when we attempt to understand change in behaviour over time. This has particular pertinence when considering change in activity participation and travel as a result of Internet use.

A pre-requisite of multitasking is that the two or more activities must be co-present. That is, an individual may undertake two activities simultaneously, but s/he cannot be in two locations simultaneously, thus the need for co-presence of multiple activities. A key opportunity stemming from Internet use arises from the ability to 'bring' activities to the individual, rather than the individual needing to physically travel to the activity - the individual can be 'virtually mobile'. This can enable the simultaneous conduct of multiple activities, both online and offline, at a single location. Thus, potentially, Internet use allows improved access to a greater number of activities, allowing the individual 
to overcome the time/space constraints associated with an activity and enabling participation in another, simultaneously. For example, the spatial constraints upon activity participation that are associated with childcare could be overcome through multitasking from home, online, to allow communication, education, employment, or shopping to take place simultaneously, potentially decreasing aspects of social exclusion.

It is equally possible, however, that multitasking may not be an opportunity but a burden, increasing stress and decreasing well-being by 'contaminating' primary activities or increasing pressure to participate where participation is undesirable. Or, perhaps, the multitasked activities may be inconsequential - much of the secondary activity time recorded in the limited number of studies of multitasking to date is that spent in 'passive leisure' - for example, listening to music, or watching television. Whilst increased participation in passive leisure may increase well-being or the enjoyment of the primary activity, the implications for social exclusion may be negligible. Finally, if access to multitasking is differential within the population, inequality in activity participation could increase.

With regard to travel, through multitasking, the Internet may enable greater activity participation, without recourse to increased physical mobility, thus suppressing future growth in demand, as suggested in earlier research by the authors (Kenyon et al, 2003). In allowing concurrent activity conduct at one location, there may be less need for travel and this reduction in travel may in turn allow greater activity participation, whilst the ability to conduct additional activities whilst travelling may facilitate greater inclusion still. However, it is equally possible that this will free-up time for more travel; or that the ability to multitask whilst travelling will increase general mobility (Lyons and Urry, 2005).

Whichever outcome, the above discussion illustrates that to study change in activity participation, including personal travel, the complexity of time use must be embraced. An examination of primary activities alone could misrepresent - disguising or enhancing the appearance of - change. If activities are not simply substituted but, rather, combined, the failure to recognise simultaneous activities will present a false picture of activity participation, leading to erroneous conclusions of cause and effect.

Therefore, multitasking forms the focus of this paper. The paper seeks to introduce the concept of multitasking to travel behaviour research and, more specifically, to the study of the impacts of the Internet. As such, it is exploratory in nature and is framed by three elements: a summary review of literature; supporting findings from an empirical study (which confirms the importance of this 'forgotten dimension'); and theoretical and methodological discussion. The paper shares insights, highlighting the 
importance of a consideration of multitasking for the field and exploring methodological challenges and analytical difficulties. In so doing, the authors seek to confirm the centrality of multitasking to daily activity and travel behaviour and, thus, to promote debate regarding the implications of such insights for our understanding of travel behaviour and behavioural change.

The paper proceeds through four further sections and is structured as follows. First, a review of the multitasking literature is presented. Next, methodological and sample details are provided. Findings are presented, which confirm the prevalence of multitasking amongst the authors' study sample. Primary data highlight the extent of multitasking and analysis by activity type, including the differences between online and offline activities, is considered. A discussion of the implications of these results for research into the impacts of ICTs upon travel and social exclusion follows.

\section{Multitasking: an overview of the literature}

There are few published studies in the time use or transport literature which consider the double counting of time, through multitasking. Termed variously simultaneous activities, overlapping activities, concurrent activities, parallel activities, primary and secondary activities, multitasking and polychronic time use (Ironmonger, 2003), this phenomenon has long been recognised as important (Szalai, 1972), yet it is only in the past decade that time use researchers have begun seriously to both record and analyse related data. Indeed, Gershuny and Sullivan (1998), in their commentary on time use research, suggest that the failure to properly account for polychronic time use and the analysis of time as though it were monochronic is a key weapon in the armoury of its critics. Bittman and Wajcman (2000), in their study of the impacts of multitasking upon gender equity in leisure time, suggest that avoidance of multitasking in research is primarily due to methodological difficulties in the collection of such information - and the variable quality of the data, if collected. Kitterod (2001) goes further to express concerns that the recording of secondary activities can negatively affect the quality of the primary activities data, considering that, given that most analysis focuses upon primary activities only, it may be appropriate to avoid recording of secondary activities altogether, in order that the quality of primary data be maximised. Furthermore, Ironmonger (2003) considers the difficulties inherent in analysing data on secondary activities, suggesting that such issues have actively prevented research in this area. Each of these concerns perhaps explains the absence of secondary activity data in the majority of surveys. 
Whilst there is debate about the extent to which individuals can truly multitask (reviewed in Hungerford, 2001 and Ironmonger, 2003), there can be little doubt that, in the time episodes used in the majority of surveys, individuals can and do combine activities, both actively and passively. In a time when more than 50 per cent of the adult population agrees with the statement, 'I am often under time pressure in my everyday life' (Kreitzman, 1999), more people appear to be refraining from choosing between activities, seeking instead to perform activities simultaneously, thus 'trying to squeeze more than a day's worth of activities into any one 24-hour period' (Floro and Miles, 2001). There is consensus in the literature that failure to recognise this simultaneous conduct of activities has distorted the picture of popular time use, leading to a biased account of the amount of time that people devote to different activities. For example, Ironmonger (2003) cites a study by Bittman and Pixley in suggesting that 75 per cent of time spent in childcare is as a secondary activity. Thus, studies recording only primary activities grossly underestimate time spent in childcare. The same author suggests that personal interaction, communications and passive leisure are similarly underreported, each vital to the study area under consideration by the present authors. It can also lead to errors in measuring change in activity participation, suggesting substitution effects where in fact activities are added to daily life (Floro and Miles, 2003). In this sense, activity participation is no longer reduced to a zero sum game, in which the addition of an activity requires the subtraction of another. Rather, the complexity of time use is recognised and embraced. Thus, studies have shown that up to 95 per cent of the population report multitasking each day (Hungerford, 2001). For approximately one third of the day, people report participating in more than one activity concurrently (ibid; also Bittman and Wajcman, 2000; Floro and Miles, 2001; Ruuskanene, 2004; using data from 1979, Michelson and Frederick (2004) found this figure to be 44 per cent).

The above studies identify the principal activities that individuals have recorded as secondary activities - and thus underreported when only primary activities are considered - to be childcare, domestic work, passive leisure and communications activities. Through analysis of multitasking, these studies have revealed the true extent of gender inequity in unpaid productive work; the contamination of women's leisure time; the use of passive leisure to increase enjoyment of certain tasks; the productivity of elderly adults; and the impacts of multitasking for stress and well being. Thus, through consideration of multitasking, these studies have revealed a greater extent of factors that potentially contribute towards social exclusion, including greater inequality in unpaid work than previously recognised, reduced leisure 
time and increased stress - yet they have also introduced the idea of positive contamination of activities through the introduction of passive leisure. Such findings could expose greater exclusion in society than previously recognised through the consideration of primary activities alone, or greater inclusion, respectively. However, none of the above studies incorporate consideration of the impacts of ICTs (and in particular the Internet) upon time use, being primarily based upon data from the 1990s and earlier.

Few studies to date have considered the phenomenon of multitasking whilst travelling. Rather, trips have traditionally been seen to constitute necessary but unproductive periods of time, functional only in their accessibility role in relation to the destinations reached. The task of travelling has tended implicitly to be assumed to preclude other tasks being undertaken simultaneously. In his single-subject ethnography, Laurier (2003) discusses the use of travel time by mobile workers, describing the (disturbing) level of multitasking undertaken by 'Ally’ whilst driving, including reading emails, arranging meetings and communicating with clients on the telephone. Whilst not suggesting that this level of multitasking is commonplace across the population, Laurier implies that it is widespread amongst mobile office workers. Bull (2003) considers the use of sound whilst travelling, highlighting the multiple roles of music during the journey and the use of travel time to communicate with others. And a study into travel time use, currently in its infancy, is discussed by Jain and Watts (2004) and Lyons and Urry (2005), the latter identifying a range of types of activities that can be conducted whilst travelling (with a focus upon travel by public transport). Jain (forthcoming) further discusses the use of time during 'equipped waiting', examining the multiple tasks undertaken during interchange periods of journeys. These studies highlight the increase in time use efficiency associated with multitasking on the move, as travel time and activity time are combined, potentially reducing the exclusionary disbenefits of high levels of travel, yet perhaps increasing the risk of exclusion for those without such travel time, those who are unable to effectively use their travel time, or to use multitask-compliant means of travel. As in the discussion of the potential effects of multitasking above, these effects are likely to be structured along traditional lines of inequality.

The above multidisciplinary review confirms the importance of secondary activities in every day life. The study to date of multitasking has pointed to fundamental flaws in our understanding of daily activity participation in society, revealing: (1) the underreporting of key activities; (2) that the tendency to misrepresent activity participation is more pronounced for certain key groups; and (3) the flawed measurement, and thus misrepresentation, of change. This has clear implications for the activity-based 
theory of traveller behaviour, for if we do not understand what people are doing, we cannot fully understand their motivations for travel, or for the use of virtual mobility as a means of access.

This paper now turns to present empirical evidence from a diary-based study involving c. 90 participants, which supports the above assertions, revealing the central importance of multitasking and highlighting the underreporting of key activities, by key groups, when primary activities alone are considered. In light of this additional evidence the following section will provide a discussion of the potential importance of the misrepresentation of activity participation to the study of the impacts of Internet use upon travel behaviour and social participation, alongside the further challenges of research into multitasking.

\section{Methodology and sample composition}

Whilst diaries have been used in research for many years, as travel, activity, time use and communications diaries, a cross-disciplinary review of existing diaries revealed that none of these methodological approaches allowed participants to record their activities to the level of detail necessary to simultaneously assess the accessibility, mobility and social impacts of virtual mobility. An 'accessibility diary' was developed for this study to address these needs (for a full discussion and justification of the methodology, see Kenyon, 2004a; for a focus group-based study of its utility, Kenyon, 2004b). The diary is presented in Figure 1. The activity codes - key to the simplicity of the survey instrument for participants, yet the richness of the data gathered - are given in Figure 2.

Figures 1 and 2 inserted about here, please.

The definition of multitasking used within this research - the simultaneous conduct of two or more activities, during a given time period - reflects the tool used to measure multitasking within this study. In common with the studies reviewed in Section 2, participants record multitasking within the context and time frame of their primary activity. This was designed to allow analysis of the nature of activities being 'twinned' during multitasking and summing of time spent in secondary activities, providing a number of means of assessing the nature of time 'gained' through multitasking. Accuracy in terms of the exact timing of multitasked activities was sacrificed in favour of reduced respondent burden. Thus, where 
participants record a secondary activity duration as ten minutes within a primary activity of 60 minutes, the accessibility diary does not provide information regarding when the multitasking took place within that time period or, indeed, if multitasking was a continuous activity or, rather, was conducted (for example) in two separate time periods of five minutes each. Discussion reflecting upon the efficacy of this approach, in light of the analysis, is given in Section 5. Participants were instructed to decide for themselves which activity is primary and which, when applicable, are secondary.

Participants were asked to complete the diary for seven consecutive days. The study will be repeated three times, at six-monthly intervals. This paper reports evidence from the first wave of the study, which took place in March, 2004. In the first wave, 92 diaries were distributed; 90 were accepted; and 87 diaries were returned. 86 were acceptable for inclusion in data analysis, providing a total of 598 diary days.

The sample was determined following a one-year feasibility study (reported in Kenyon et al, 2002, 2003), which hypothesised at its completion the importance of the following factors in determining spatial accessibility, access to physical and virtual mobility, thus also activity participation, social participation and personal travel: income; Internet access and experience; mode use; and residential location. This study aimed to recruit participants representing this range of variables. Six locations in the south west of England were chosen on the basis of population size, transport services provision, profile of local amenities and proximity to other settlements. The locations - Stogumber, Somerset; Sandford, Devon; Crediton, Devon; Taunton, Somerset; outer Bristol suburbs; and inner city Bristol - decrease in rurality from a small hamlet with a population of 500 to a city with a population nearing 0.4 million.

It was not the aim to gain a nationally representative sample of participants. The pursuit of representativeness in the sample was not considered the most appropriate way in which to make theoretical and analytical advances in relation to this research (Behrens, 2003; Mason, 1996). Rather, the study aimed to gain a sample representing the four factors deemed key to the research area. In this sense, the sample was designed to be 'fit for purpose' (May, 2001). Participants were selected according to their degree of fit with criteria based upon the factors above, recruited using a variety of techniques including snowballing, the print and broadcast media and with the assistance from an external public body. The sample has, nevertheless, been closely examined with regard to representativeness. This analysis gives a profile unrepresentative of the national UK population, but more in keeping with that of the national Internet user profile for income, age, education, mode use and Internet experience and use (for full 
discussion of the sample strategy, including national statistics regarding each of the above variables, see Kenyon, 2004c).

The following section presents evidence for the importance of multitasking, for research into participation, travel and the impact of Internet use, beginning to consider the effects of multitasking for each. Study findings support the three hypotheses emergent from the above review of the literature, namelt that:

1. failure to consider multitasking leads to the underreporting of key activities;

2. the tendency to misrepresent activity participation is more pronounced for certain key groups; and

3. lack of awareness of multitasking can lead to the flawed measurement and thus misrepresentation of change.

Study findings further suggest that multitasking behaviour varies by the primary activity's offline or online status. Taken together, the empirical evidence confirms that the consideration of multitasking is likely to have important implications for the study of travel, Internet use and interactions between the two.

\section{Study findings}

\subsection{How prevalent is multitasking?}

All participants report multitasking at some stage during the week. An incidence of multitasking (with at least one activity recorded in parallel with a primary activity) is recorded on 99 per cent (590 out of 598) of days. Participants reported instances of undertaking three or more parallel activities at any one time on 81 per cent of days (486 days); and four parallel activities on 52 per cent of days (312 days). This suggests that multitasking is extremely common amongst this sample. As shown in Table 1, multitasking 'adds' almost seven hours to each day, totalling an addition of more than 48 hours to the average week. Thus, for this sample, multitasking 'adds' 46 per cent more time to each waking day.

Table 1 inserted about here, please. 


\subsection{How important is multitasking?}

Table 2 begins to highlight the importance of multitasking, indicating the mean number of minutes that participants spend undertaking activities, grouped by activity category ${ }^{5}$. The percentage of time spent in each category is also given. The Table demonstrates the distorted picture of time use and activity participation that emerges when only primary activities are considered. Considering the share of overall time use attributable to each activity type, it is particularly noticeable that the recording of secondary activities increases the share of communications activities, from four per cent of total average time allocation, to 17 per cent. Formal activities see a considerably reduced share, with the percentage of time allocated to household/personal and travel activities also reduced. The recording of multitasking is seen to: increase the absolute time spent communicating more than six fold; almost double the amount of time spent in entertainment/recreation and information search activities; and increase time spent shopping and in household/personal activities by 50 and 60 per cent, respectively. It is notable that the activities in which time use is most underreported when primary activities alone are considered are those that have been hypothesised to be susceptible to travel substitution effects, because of their propensity to be performed using ICTs: communicating; entertainment/recreation; information search; and shopping.

Thus, in support of hypothesis (1), study findings confirm that participants’ activity participation profiles are substantially distorted when primary activities alone are considered. Furthermore, these underreported activities are likely to be of central importance to the Internet and travel behaviour debate.

Table 2 inserted about here, please.

\subsection{Determinants of multitasking}

Previous studies have highlighted differing propensity to multitask according to factors including age, educational attainment, employment status, gender, household lifecycle and income (Floro and Miles, 2003). Results from this study are mixed, but the data do hint at relationships between certain characteristics and multitasking.

Perhaps surprisingly, bivariate analysis undertaken for this study fails to find a significant relationship between propensity to multitask and gender. Multitasking is seen to increase with age, into middle age,

\footnotetext{
${ }^{5}$ Because of the structure of the data set, in common with other time use studies, it has been necessary to combine activities within each activity category. The activity content of each category is given in Figure 2.
} 
before declining into old age, suggesting a strong link with the life cycle ${ }^{6}$. This is supported by a significant increase in multitasking where there are children in the household, aged both under 12 and under 16. People who are employed multitask to a greater extent than those who are unemployed, yet this could be linked to the structure of the survey instrument, which instructs participants to record work as a continuous, unbroken activity, unlike any other activity.

Income is positively correlated with multitasking, such that those with higher incomes tend to multitask more ${ }^{7}$. The relationship between residential location and multitasking is less clear. Multitasking appears to increase with the availability of amenities and services. Participants residing in the large town and inner suburbs, associated with high availability of amenities and services, multitasked significantly more than those in the village, small town and outer suburbs. However, this relationship is not simply one related to settlement size or density: high levels of multitasking were recorded in a sample living in a very small village.

Thus, these data further support hypothesis (2), suggesting differential propensity to multitask according to key characteristics, such that the effects (which could be both positive and negative) of multitasking are likely to be unequally distributed across society. It is uncertain whether or not tendency to multitask is linked to ability or desire so to do. However, either way and in light of the unequal distribution of multitasking, we can suggest that technologies enabling greater multitasking are likely to have important implications for social (in)equality.

\subsection{Multitasking, mobility and the Internet}

That use of the Internet might facilitate a higher incidence of multitasking is not apparent at an overall aggregate level. There is no clear relationship, following bivariate analysis for this sample, between Internet experience, measured in terms of both years since first use and years since connection at home, and multitasking. Notably for this study no evidence has yet been found of a link between time spent multitasking and time spent using the Internet each day. However, there is evidence of a link between the propensity to multitask and the online/offline status of the primary activity. In addition, there is a link between the number of minutes spent multitasking and the number of minutes spent travelling each day. These findings are considered further, below.

\footnotetext{
${ }^{6}$ Unless otherwise stated, chi square tests suggest that all observations are significant at $\mathrm{p}<.001$.

${ }^{7}$ Chi square tests revealed relationships between income quartiles and multitasking, significant at $\mathrm{p}$. $<01$. Correlation 0.26 , significant at p. $<001$. Measurement of multitasking is in duration and not frequency of occurrence.
} 


\subsubsection{Multitasking and the primary activity}

Results suggest that the tendency to multitask appears to be heavily influenced by the nature of the primary activity, including whether or not the primary activity is online or offline. Multitasking does not appear to be randomly distributed across different activity types. It therefore follows that, in support of hypothesis (3), a focus purely on primary activities when considering change in activity participation will result in a distorted picture of the nature of this participation. Furthermore, it is likely that a different picture of the impacts of ICTs will emerge if secondary activities are also considered.

Table 3 inserted about here, please.

Table 3 illustrates this differing tendency to multitask by activity type. An initial focus upon the column 'Total' suggests that participants are multitasking for more than half of the duration of their primary activities, for the majority of activity types. Both entertainment/recreation activities and, more pertinently for this study, travel, are highly likely to be accompanied by the concurrent undertaking of other tasks. Table 3 suggests that for 84 per cent of the time that an individual is travelling, they will be conducting at least one parallel activity. Further, 75 per cent of time spent primarily in household/personal activities is spent multitasking; 60 per cent of information search time; 56 per cent of formal activity time; 49 per cent of shopping time; and 41 per cent of communicating time.

In Table 3 we aggregate activities into two broad groups, depending on whether the primary activity is undertaken online or offline. Whilst at the aggregate level it appears that offline primary activities are more likely to be multitasked than online primary activities (71 and 60 per cent of the time, respectively), a breakdown by activity category reveals considerable variation (as shown in the latter two columns of the Table). Thus, multitasking is more likely to occur when participants are communicating online, than when they are communicating offline. Online primary activities are also multitasked more often than offline primary activities in the majority of the other activity categories including: formal; information search; and shopping, for which online shopping activities are conducted in parallel to other activity almost twice as often when the shopping is online than when it is offline. However, entertainment/recreation activities, other activities and household/personal activities as primary activities are conducted in parallel to a greater extent when they are undertaken offline. Household/personal 
primary activities undertaken offline are multitasked more than six times as often as when undertaken online.

Table 4 further explores the relationship between activities and their propensity to be conducted online or offline, highlighting differences therein. The Table illustrates the extent to which tendencies in the choice of secondary activity type differ by whether or not the primary activity is online or offline. For example, when the primary activity is online, 44 per cent of the time spent in secondary activities is in entertainment/recreation activities. When the primary activity is offline, participants spend 36 per cent of their total secondary activity time in these activities. The results suggest that there is little change in the relative prevalence of the different secondary activity types between the primary activity being undertaken online or offline.

These results confirm that participation in secondary activities is influenced by the nature of the primary activity, in terms both of the activity type and its offline/online status. Empirical evidence suggests that certain activities are more likely to be multitasked; and that the primary activity influences the nature of the accompanying secondary activity. Further, it appears that mode of access - that is, physical or virtual access - to activities influences the likelihood that multitasking will take place.

Table 4 inserted about here, please.

\subsubsection{Travel and multitasking}

Table 5 presents information about multitasking whilst travelling. Findings suggest that travel is most often teamed with communication, entertainment/recreation and household/personal activities. It can be suggested that the ability to multitask can influence the attractiveness of travel as an accessibility option and perhaps that travel itself enables participation in the given secondary activity, each with important implications for the promotion of virtual accessibility. Returning to Table 4, findings suggest that, when the primary activity is online, two per cent of secondary activity time is spent in travel activities, perhaps supporting a role for Internet use in travel activities. This said, twice as many offline activities were twinned with travel.

Table 5 inserted about here, please. 


\section{Discussion}

Empirical evidence from this study confirms the prevalence of multitasking amongst this sample. Almost without exception, multitasking is occurring on a daily basis for all individuals, to the extent that it seems to 'add' 46 per cent more time or time use to the waking day. This paper suggests that the empirical evidence presented above confirms that the consideration of multitasking is likely to have important implications for the study of travel behaviour and the impact of Internet use thereon.

Firstly, given that the failure to consider multitasking leads to the underreporting of key activities, it follows that only accounting for the primary activity in activity/travel behaviour studies will distort the picture of daily activity behaviour and thus of motivations for travel. Secondly, following from this, findings confirm that the tendency to misrepresent activity participation through the failure to account for multitasking is more pronounced for certain key groups, such that the understanding of activity and travel behaviour for groups traditionally excluded from consideration in transport systems and research will continue to be inadequate. Thus, the phenomenon of mobility-related exclusion, itself a result of the historic invisibility of such groups to planners, practitioners and researchers, is likely to continue to be a problem if multitasking is not accounted for. Thirdly, a lack of awareness of multitasking is likely to lead to the flawed measurement and thus misrepresentation of change in response to external stimuli, which is particularly pertinent for the study of change in response to the availability and use of physical and virtual mobility.

Study findings confirm that multitasking is not evenly distributed across activity types, but that it varies in both quantity and nature, by activity type. Furthermore, there is an 'Internet effect' upon activity participation, suggesting that multitasking behaviour varies by the primary activity's offline or online status. However, the aggregation of activities into activity categories, which is in line with published time use studies and is necessary for statistically meaningful results, is likely to be masking subtleties of both participation and change. Thus, such analysis is likely to preclude assessment of the pre-conditions for multitasking. What are the fundamental attributes of an activity that are relevant in understanding the appropriateness of activities, whether online or offline, for multitasking? That is, which combinations of activities work well together, which do not - and why? Addressing such questions is likely to be important for developing a better understanding of travel behaviour and in turn the possibilities for behavioural modification. In light of this, it may be appropriate to challenge the pursuit of statistically meaningful analysis and, in a theme which will be returned to towards the end of this section, to question 
the extent to which we can ever obtain and accurately analyse the depth of data that we would like to have to enable the analysis of all the possible influences of activity and travel behaviour (Axhausen, 1998).

This paper hypothesises that there are three attributes of activities that may be important to the extent to which multitasking is both possible and desirable, namely:

1. the degree of locational dependence;

2. the degree of continuity of engagement; and

3. the degree of active attention.

Locational dependence refers to the extent to which activities are required to be undertaken at particular locations. A high degree of locational dependence can preclude the simultaneous conduct of activities with differing locational constraints. Thus, offline grocery shopping cannot take place at the same time as preparation of a meal at home. However, online grocery shopping could take place at home at the same time as preparing a meal, because of the reduced locational dependence of one of the activities (grocery shopping).

This example also illustrates the relevance of the degree of continuity of engagement in the possibility of multitasking. Preparing the meal is unlikely to require continuous use of time throughout but, rather, intermittent attention. Likewise, online grocery shopping can be continuous in the sense of being logged into a website, but time devoted to the task of shopping can be intermittent. Thus, discontinuity of engagement may be a determinant of multitasking. Finally, the third factor highlighted above refers to the degree of active attention required for the task. Thus, a number of studies reviewed in Section 2 highlight the underreporting of childcare when multitasking is not considered. Similarly, many participants in this study record childcare as a secondary, rather than a primary activity. These findings perhaps reflect the degree of active attention necessary for this task. The number of minutes that a carer is actively involved in childcare, as a proportion of the day, have been shown to be substantially less than the time spent in passive supervision ${ }^{8}$. Thus, multitasking is more likely to be possible for activities requiring less active attention.

With regard to the effects of multitasking, whilst we can conclude that multitasking, by its very nature, enables more activity participation minutes per day, the effect of this increase in activity minutes remains unknown. Possible positive and negative social and travel effects have been hypothesised above and include, with regard to travel, that the conduct of multiple activities whilst travelling (proven by the

\footnotetext{
${ }^{8}$ Although, of course, this is dependent on a number of factors, including the age of the child.
} 
empirical evidence in Section 4 may suggest that travelling enables multitasking, thus reducing the disutility of travel and encouraging greater mobility. With regard to the social effects, multitasking may reduce social exclusion by providing access to activities from which the individual has previously been excluded which can, in turn, directly enhance inclusion; it may increase passive leisure, decreasing the disutility of activities; or it may negatively contaminate activities, decreasing well being. However, the aggregation of activities for analysis is likely to mask such subtleties, providing further impetus for challenge to the dominant and accepted statistical tests for research in this area; and perhaps what is needed for such analysis is for an individual's value judgements to be obtained alongside a record of their time use, with attendant issues of participant fatigue. In light of the above, it is likely to be inappropriate to take the total recorded minutes of engagement in activities as in this study and to see this as a proxy for how much more people are achieving in their day through multitasking, without caveats with regard to quality and meaningfulness. Such methodological issues demand attention if study in this field is to progress.

Furthermore, our analysis has revealed large variations in the number of both primary and secondary activities recorded by each participant. Focus group-based research into the usability of the accessibility diary was undertaken. When questioned about their completion strategies, considerable variation emerged, despite one-to-one tuition and the provision of instructions that had been piloted to check their clarity (Kenyon, 2004b). It is also important to note that participants were instructed to judge for themselves what they considered to be the primary activity and what were the secondary activities in instances of multitasking. Focus group discussions revealed that individuals applied different rationale to identifying the primary activity - and the accessibility diary methodology precludes knowledge of which rationale was applied. The impact of this ambiguity is, at this stage, unknown. If diary completion is ambiguous (in terms of a consistent approach to completion across participants) then the opportunity to explore intra-wave variability (between participants) may be limited. Longitudinal, inter-wave analysis will expose the extent to which such variability is attributable to genuine differences in behaviour, or alternatively to differences in diary completion strategies, which cannot be assessed through analysis of a single, cross-sectional study. Such insights are likely to be significant in assessing the utility both of the methodological approach and of the data.

This section concludes by highlighting the theoretical barriers to methodological development which, it is suggested, have limited the effective recording and analysis of multitasking data. Perhaps the 
fundamental barrier to effective recording and analysis of multitasking has been the conceptualisation of time as a vertical construct, a framework that underlies time use and activity/travel behaviour studies and thus informs the development of data collection methodologies and analytical processes. That is, time is conceptualised hierarchically, visualised as a single column of data, through which each activity progresses sequentially, from one insulated step to another. Consideration of multitasking, however, requires the reconceptualisation of time as an horizontal, non-linear entity, rather than a vertical, linear entity - a recognition that our experience of time is broader than the single, insulated pathway that clock time constructs ${ }^{9}$. The authors suggest that existing methodologies and available analytical approaches or, rather, analytical approaches that are judged to be acceptable in the field of study - perhaps struggle to cope with this non-linear conceptualisation of time. The present study falls similarly into this theoretical trap.

Given the above observations, in addition to the above question regarding whether or not we can ever obtain the depth of data that we would like to have, it is likely to become ever more important to question the ability of survey tools to record human behaviour unambiguously and without bias. The authors suggest that this should be discussed more openly and where ambiguity might exist this should be more transparently reported and discussed, in order that analytical, methodological and theoretical advances can continue to be made.

\section{Concluding remarks}

We are in a time when transport research and policy face two important challenges: (1), the need to understand how to change travel behaviour; and (2), the prior need to understand how and why travel behaviour is changing. The research in this paper is concerned with the latter, in the context of the changing role of ICTs in society. More specifically, the paper has centred upon an understanding of how time is used for participation and, within this, of how multitasking influences daily patterns of activity and travel behaviour. Whilst the paper has discussed a number of outstanding challenges and unknowns that are yet to be resolved, it has clearly highlighted the role of multitasking in daily activity behaviour, presenting hypotheses and supporting empirical evidence to this effect. Thus, as at the start, two important questions close this paper. How much of our understanding of people's activities, travel and use of ICTs could have been and may continue to be compromised by a failure to take account of

\footnotetext{
${ }^{9}$ For more detailed discussion of the conceptualisation of time, see initially Jain and Watts, 2004.
} 
multitasking? And, is it possible to take sufficiently unambiguous and thorough account of multitasking in data collection and analysis to address this?

Further steps in this study will include closer examination of the diary data at a more disaggregated level of activity type, notwithstanding the concerns regarding statistical validity that are associated with this approach, coupled with qualitative follow-up work with the participants themselves, in order to better understand the complex interrelationships between activity participation, Internet use and personal travel. 


\section{References}

Behrens, R. (2003) Looking beyond commuter travel in Cape Town: methodological lessons from the application of an activity-based travel survey. In Stopher, P. and Jones, P. Transport survey quality and innovation. Oxford: Elsevier.

Bhat, C. R. and Koppelman, F. S. (1999) A retrospective and prospective survey of time-use research. Transportation. 26. 119-139.

Bittman, M. and Wajcman, J. (2000) The rush hours: the character of leisure time and gender equity. Social Forces. 79: 1. 165-189.

Bull, M. (2003) Automobility and the power of sound. Theory, Culture and Society. 21: 4/5. 243-259.

Floro, M. S. and Miles, M. (2001) Time use and overlapping activities: evidence from Australia. Sydney: The Social Policy Research Centre.

Floro, M. S. and Miles, M. (2003) Time use, work and overlapping activities: evidence from Australia. Cambridge Journal of Economics. 27. 881-904.

Gershuny, J. and Sullivan, O. (1998) The sociological uses of time-use diary analysis. European Sociological Review. 14:1. 69-85.

Hungerford, T. L. (2001) Just how productive are elderly adults? Evidence from Australia. Washington DC: Office of Policy, Social Security Administration.

Ironmonger, D. (2003) There are only 24 hours in a day! Solving the problematic of simultaneous time use. Proc. The 25th IATUR Conference on Time Use Research. 17-19 September, Brussels.

Jain, J. (nd) No time for a brief encounter? The politics of flows and waiting at transport interchanges. Unpublished draft.

Jain, J. and Watts, L. (2004) Travel time use in the information age: a literature review. Unpublished. Katz and Rice. (2002) The social consequences of Internet use. Mass: MIT.

Kenyon, S. (2003) Social exclusion and social inclusion. Municipal Engineer. 156: ME2. 97-104.

Kenyon, S. (2004a) Reshaping patterns of mobility and exclusion? Measuring the impact of virtual mobility upon the nature and extent of participation amongst key social groups: a methodology. Proc. Alternative Mobility Futures Conference. 9-11 January, 2004. Lancaster, UK.

Kenyon, S. (2004b) An assessment of the usability of the first wave Accessibility Diary. http://www.transport.uwe.ac.uk/research/projects/internet/internet\%20working\%20paper\%201.pdf, accessed 14 February 2005. 
Kenyon, S. (2004c) Sampling strategy. Unpublished working paper. To be available online via http://www.transport.uwe.ac.uk.

Kenyon, S., Lyons, G. and Rafferty, J. (2002) Transport and social exclusion: investigating the possibility of promoting inclusion through virtual mobility. Journal of Transport Geography. 10 : 207-219.

Kenyon, S., Rafferty, J. and Lyons, G. (2003) Social exclusion and transport: a role for virtual accessibility in the alleviation of mobility-related social exclusion? Journal of Social Policy, 31: 317338.

Kitterod, R. H. (2001) Does the recording of parallel activities in time use diaries affect the way people report their main activities? Social Indicators Research. 56. 145-178.

Kreitzman, L. (1999) The 24 hour society. RSA Journal. 147. 76-81.

Laurier, E. (2003) Doing office work on the motorway. Theory, Culture and Society. 21: 4/5. 261-277.

Lyons, G. and Urry, J. (2005) Travel time use in the information age. Transportation Research A. 39. 257-276.

Mason, J. (1996) Sampling and selecting. In Mason, J. Qualitative researching. London: Sage Publications. 83-106.

May, T. (2001) Social research: issues, methods and process. Buckingham: Open University Press.

Michelson, W. and Frederick, T. (2004) Simultaneous activity in everyday life: from accounting to explanation. Proc. 26th International Association of Time Use Research Conference. 27-29 October, 2004. Rome, Italy.

Mokhtarian, P.L. and Salomon, I. (2001). How derived is the demand for travel? Some conceptual and measurement considerations. Transportation Research A, 35, 695-719.

Ruuskanene, O. P. (2004) Essay 4. More than two hands: is multitasking an answer to stress? In Ruuskanene, O. P. An econometric analysis of time use in Finnish households. Unpublished PhD thesis, Helsinki School of Economics, Acta Universitatis Oeconomicae Helsingiensis. 189-229.

Szalai, A. (ed.) (1972) The Use of Time: Daily Activities of Urban and Suburban Populations in Twelve Countries. The Hague: Mouton. 
Figure 1. The accessibility diary.

Day(s)... Monday

\begin{tabular}{|c|c|c|c|c|c|c|c|c|c|c|c|}
\hline \multirow{2}{*}{$\begin{array}{l}\text { What did you do? } \\
\text { Please write code for } \\
\text { one main activity }\end{array}$} & \multirow[t]{2}{*}{$\begin{array}{l}\text { Start } \\
\text { time }\end{array}$} & \multirow[t]{2}{*}{$\begin{array}{l}\text { End } \\
\text { time }\end{array}$} & \multirow{2}{*}{$\begin{array}{l}\text { Where did you do it? } \\
\text { E.g. at home; at office; between } \\
\text { home and work... }\end{array}$} & \multirow{2}{*}{$\begin{array}{c}\text { Did anyone } \\
\text { else do this } \\
\text { with you? } \\
\text { Yes / No }\end{array}$} & \multirow{2}{*}{$\begin{array}{c}\text { Was anyone } \\
\text { else around } \\
\text { at the time? } \\
\text { Yes / No }\end{array}$} & \multicolumn{6}{|c|}{$\begin{array}{l}\text { What else were you doing? } \\
\text { Please enter code and duration for up to three additional activities }\end{array}$} \\
\hline & & & & & & Code & Dur. & Code & Dur. & Code & Dur. \\
\hline$H 1$ & : & 07:00 & At home & Yes & Yes & & & & & & \\
\hline $\mathrm{H} 2$ & 07:00 & $07: 30$ & 4 & No & Yes & E8 & 30 & & & & \\
\hline H3 & $07: 30$ & 07:45 & " " " & No & Yes & E8 & 15 & & & & \\
\hline T9 & $07: 45$ & 08:00 & Home to bus stop & No & No & & & & & & \\
\hline T3 & 08:00 & $08: 15$ & Bus stop to train station & No & Yes & & & & & & \\
\hline T5 & $08: 15$ & 08: 40 & Station to station & No & Yes & F1 & 20 & & & & \\
\hline
\end{tabular}


Figure 2. The activity codes.

Communicating

C1 Face to face

C2 By telephone (landline)

C3 By mobile telephone

C4 By text, or video messaging

C5 By letter

C6 By fax

C7 By email

C8 In chat room

CO Other communicating

COI Other communicating - Internet

Information search

I1 Trivia

1I Trivia - Internet

12 Window shopping

I2I Window shopping - Internet

13 Journey information

|3I Journey information - Internet

14 Employment information

14I Employment - Internet

15 Hobbies

5I Hobbies - Internet

I6 Medical (inc. NHS Direct)

I6I Medical - Internet

17 News (includes TV, newspaper)

17I News - Internet

10 Other information search

IOI Other information search Internet
Entertainment / recreation

E1 Resting, relaxing

E2 Reading

E3 Do hobbies

E4 Play sports

E5 Cinema, theatre, watch sport, etc.

E6 Social (pub, club, bingo...)

E7 Watching TV, video, DVD

E8 Listening to music, radio

E9 Travelling for pleasure

E10 Surfing (no specific purpose)

E11 Playing computer games

E0 Other entertainment / recreation

EOI Other entertainment / recreation Internet

Shopping for:

S1 Groceries (main)

S1I Groceries (main) - Interne

S2 Groceries (top up)

S2I Groceries (top up) - Internet

S3 Clothing

S3I Clothing - Internet

S4 Music

S4I Music - Internet

S5 Journeys (not holidays)

S5I Journeys (not holidays) - Internet

S0 Other shopping

sol Other shopping - Internet
Formal activities

F1 Paid work

F2 Education

F2I Education - Internet

F3 Voluntary work

F3I Voluntary work - Internet

F4 Religious activity

F4I Religious activity - Internet

F5 Campaigns, civic

F5I Campaigns, civic - Internet

F0 Other formal activities

FOI Other formal activities - Internet

Travel

T1 Driving the car

T2 Travelling in car as passenger

T3 Travelling on bus

T4 Travelling by coach

T5 Travelling on train

T6 Riding motorcycle or similar

T7 Travelling in taxi

T8 Riding bicycle

T9 Walking

T10 Travelling on an aeroplane $\underline{\text { Household and personal }}$

H1 Sleeping

$\mathrm{H} 2$ Personal care

H3 Eating, drinking, inc. preparation

H4 Housework, household maintenance

H5 Childcare

$\mathrm{H} 6$ Other caring activities

H7 Running errands (e.g. posting a letter)

H8 Escort (includes school run)

H9 Banking, financial

H9I Banking, financial - Internet

H10 Medical (includes GP, hospital)

HO Other household and personal

\section{Other / Personal}

O1 Other activities

O1l Other activities - Internet

O2 Personal activities

O2I Personal activities - Internet

TO Other travel 
Table 1. Mean number of minutes spent in secondary activities, per person, per day

\begin{tabular}{lc}
\hline & $\begin{array}{c}\text { Mean in minutes per day } \\
\text { (hours) }\end{array}$ \\
\hline Secondary activity 1 & $287(4.8)$ \\
Secondary activity 2 & $90(1.5)$ \\
Secondary activity 3 & $35(0.6)$ \\
\hline Total & $\mathbf{4 1 2}(\mathbf{6 . 9 )}$ \\
\hline
\end{tabular}


Table 2. Mean time spent in primary and secondary activities per person per day

\begin{tabular}{|c|c|c|c|c|c|c|}
\hline Activity & $\begin{array}{c}\text { Primary } \\
\text { mean } \\
\text { (minutes per } \\
\text { day) }\end{array}$ & $\begin{array}{c}\text { Secondary } \\
\text { mean } \\
\text { (minutes per } \\
\text { day) }\end{array}$ & $\begin{array}{l}\text { Primary plus } \\
\text { secondary } \\
\text { (minutes per } \\
\text { day) }\end{array}$ & $\begin{array}{c}\text { Secondary } \\
\text { activity time } \\
\text { as \% of } \\
\text { primary } \\
\text { activity time }\end{array}$ & $\begin{array}{c}\% \text { of total } \\
\text { primary } \\
\text { activity time }\end{array}$ & $\begin{array}{c}\% \text { of total } \\
\text { primary plus } \\
\text { secondary } \\
\text { activity time }\end{array}$ \\
\hline Communicating & 38 & 235 & 274 & 618 & 4 & 17 \\
\hline $\begin{array}{l}\text { Entertainment/ } \\
\text { recreation }\end{array}$ & 262 & 242 & 504 & 92 & 28 & 31 \\
\hline Formal & 268 & 15 & 284 & 6 & 28 & 18 \\
\hline $\begin{array}{l}\text { Household/ } \\
\text { personal (excl. } \\
\text { sleeping) }\end{array}$ & 245 & 123 & 369 & 50 & 26 & 23 \\
\hline $\begin{array}{l}\text { Information } \\
\text { search }\end{array}$ & 16 & 14 & 30 & 88 & 2 & 2 \\
\hline Shopping & 20 & 12 & 32 & 60 & 2 & 2 \\
\hline Travel & 92 & 24 & 116 & 26 & 10 & 7 \\
\hline Other/personal & 6 & 4 & 10 & 67 & 1 & 1 \\
\hline Total & 947 & 669 & 1619 & - & 100 & 100 \\
\hline
\end{tabular}


Table 3. Percentage of primary activity time involving multitasking, by activity category and online/offline status

Secondary activity time as a percentage of primary activity time (\%)

\begin{tabular}{lll} 
Primary activity category & Total $^{1}$ & Primary is online \\
\cline { 2 - 3 } & Primary is offline & \\
\end{tabular}

Communicating

Entertainment/ recreation ${ }^{4}$

Formal $^{4}$

Household/ personal (excl.

sleeping) ${ }^{4}$

Information search

Shopping

Travel

Other/personal

Any online activity

Any offline activity
51

66

86

12

\footnotetext{
${ }^{1}$ Minutes per week spent undertaking secondary activities whilst undertaking primary activities, in the given primary activity category, as a percentage of the total minutes per week spent in that activity.

${ }^{2}$ Minutes per week spent undertaking secondary activities whilst undertaking online primary activities, in the given primary activity category, as a percentage of the total minutes per week spent in that online activity.

${ }^{3}$ Minutes per week spent undertaking secondary activities whilst undertaking offline primary activities, in the given primary activity category, as a percentage of the total minutes per week spent in that offline activity.

${ }^{4}$ Online time as percentage of total time for primary activity is very low for Entertainment/Recreation (0.6), Formal (0.2) and Household/personal (0.2), thus 'Total' and 'Primary is offline' values appear the same.
} 
Table 4. Comparison between the primary activity being online and offline of the distribution of multitasking across different types of secondary activity (shown as percentage of total secondary activity time associated with primary online activity and offline activity respectively)

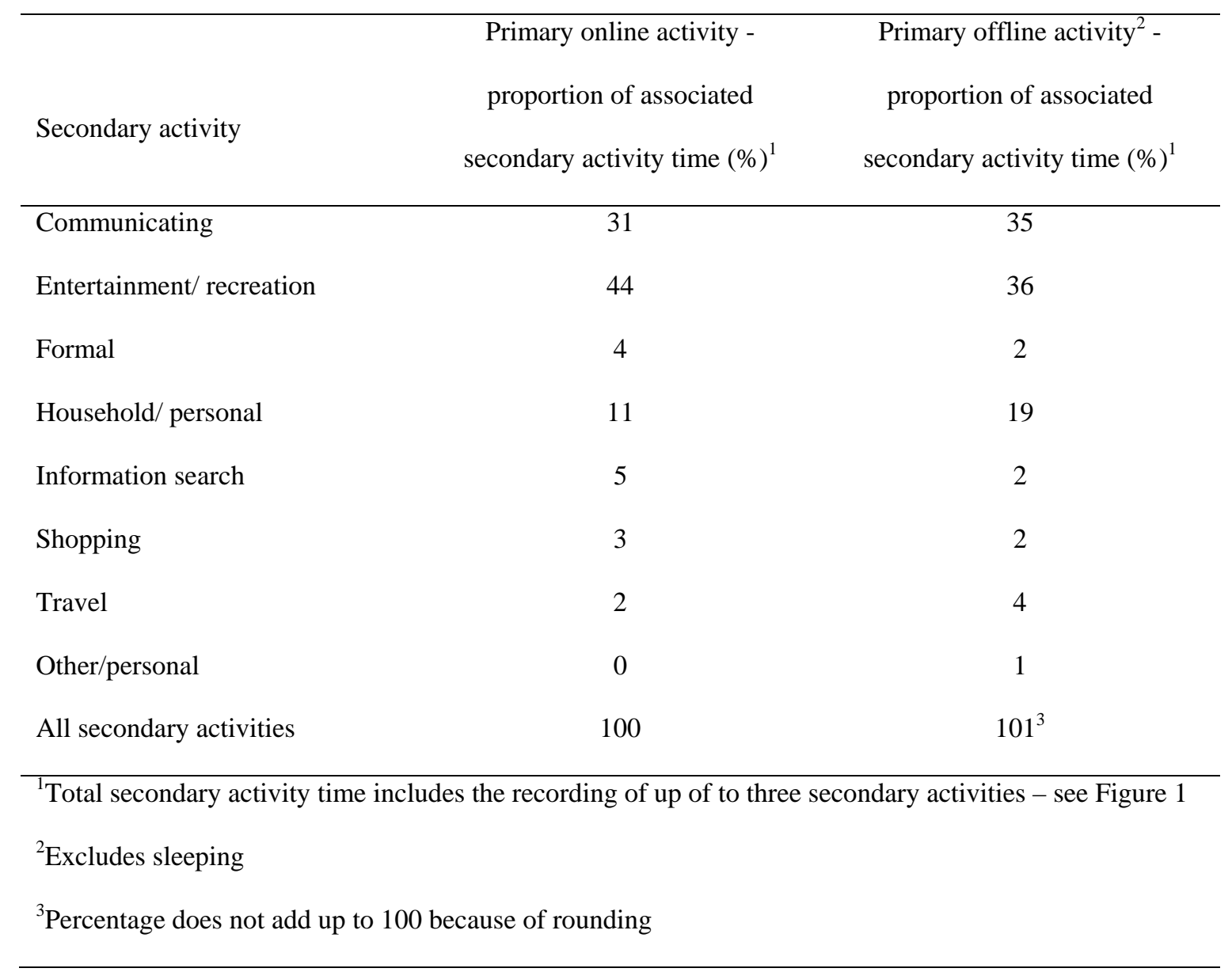


Table 5. Distribution across secondary activity types of multitasking whilst travelling (shown as percentage of total secondary activity time associated with the primary activity of travel)

Proportion of secondary activity
time associated with travel (\%) ${ }^{1}$

Communicating

35

Entertainment/ recreation

41

Formal

3

Household/ personal

15

Information search

1

Shopping

3

Travel

3

Other/personal

0

${ }^{1}$ Total secondary activity time includes the recording of up of to three secondary activities - see Figure 1. Percentages do not add up to 100 because of rounding 